\title{
Mammalian Target of Rapamycin Signaling Pathway Changes with Intestinal Epithelial Cells Renewal Along Crypt-Villus Axis
}

\author{
Huansheng Yang ${ }^{a, b, c}$ Xia Xiong ${ }^{b}$ Xiaocheng Wang ${ }^{b}$ Yulong Yin ${ }^{a, b}$ \\ aAnimal Nutrition and Human Health Laboratory, School of Life Sciences, Hunan Normal University, \\ Changsha, ${ }^{b}$ Chinese Academy of Science, Institute of Subtropical Agriculture, Research Center \\ of Healthy Breeding Livestock \& Poultry, Human Engineering \& Research Center of Animal \& \\ Poultry Science, Key Lab Agroecology Processing Subtropical Region, Scientific Observational and \\ Experimental Station of Animal Nutrition and Feed Science in South-Central, Ministry of Agriculture, \\ Changsha, 'Fujian Aonong Bio-Technology Co, Ltd, Xiamen, China
}

\section{Key Words}

mTOR • Intestine $\bullet$ Epithelial cells $•$ Crypt-villus axis $•$ Antioxidant capacity

\begin{abstract}
Background/Aims: Understanding the mechanism that involves in regulating epithelial cells renewal is the fundamental of regulating intestinal mucosa development and functions and related diseases. The mechanistic target of rapamycin (mTOR) signaling pathway involves in controlling various major processes by integrating intracellular and extracellular cues. The present experiment was conducted to test the correlation between the mTOR signaling pathway and intestinal epithelial cells renewal along crypt-villus axis (CVA). Methods: Intestinal epithelial cells were sequentially isolated from the jejunum of piglets along CVA, and the amount or phosphorylation level of proteins involved in cell cycle, mTOR signaling pathway, gene expression, and the antioxidant capacity in the isolated cells were measured. Results: The results showed that the amount of proteins involved in cell cycle decreased from crypt to villus tip. The amount or phosphorylation level of proteins related to mTOR signaling pathway in intestinal epithelial cells mainly decreased during maturation along CVA. The amount of proteins involved in gene expression and the antioxidant capacity also decreased from crypt to the top of villi. Conclusions: These results indicate that the mTOR signaling pathway may be involved in regulating the intestinal epithelial cells renewal along CVA and it may partly through affecting the antioxidant capacity and gene expression of intestinal epithelial cells. Further histological verification is needed to confirm the results of the present experiments.
\end{abstract}




\section{Cellular Physiology Cell Physiol Biochem 2016;39:751-759 \\ \begin{tabular}{l|l} 
and Biochemistry & DOI: 10.1159/000445665 \\
Published online: July 27, 2016 & $\begin{array}{l}\text { C } 2016 \text { The Author(s). Published by S. Karger AG, Basel } \\
\text { www.karger.com/cpb }\end{array}$
\end{tabular} \\ Yang et al.: mTOR Signaling Pathway Along Crypt-Villus Axis}

\section{Introduction}

The small intestinal mucosa is a layer of epithelium that can be divided into two parts, the crypt that is the flask-shaped submucosal invaginations, and the villi which is the finger-like luminal protrusions [1]. These morphologically distinct compartments also have different roles in intestinal functions $[1,2]$. The crypt contains stem cells, which give rise to progenitor cells, and the progenitor cells via rapid proliferation before cell cycle arrest and ultimately differentiated into absorptive enterocytes, endocrine cells, goblet cells, and Paneth cells [1, 2]. The absorptive enterocytes are the major types of epithelial cells in intestinal epithelium, which constitute more than $90 \%$ of the epithelial cells [3]. The villus epithelial cells undergo rapid renewal via highly coordinated processes of cellular proliferation, lineage-specific differentiation, and apoptosis along the crypt-villus axis (CVA). The continual renewal of epithelial cells along CVA ensures the functions of small intestine [2]. Many experiments were conducted to study the mechanisms that were involved in regulating the renew of intestinal epithelial cells, and various signaling pathways were identified, including Wntbeta-catenin-TCF, BMP-TGF-beta-SMAD, Notch and its downstream factors HES1 and Atoh1, and hedgehog signaling and so on $[1,4]$. However, the signaling networks that involve in regulating cellular physiology and functions were much more complicated than expected. New signaling pathways and new functions of known signaling pathways are continually identified.

The mechanistic target of rapamycin (mTOR) signaling pathway is an serine/threonine protein kinase which belongs to the family of phosphoinositide-3-kinase (PI3K)-related kinases [5]. The mTOR signaling pathway is highly conserved from yeast to humans and involves in integrating intracellular and extracellular cues (e.g. growth factors, energy, amino acids, stress, and oxygen) to control various major processes, such as protein synthesis, lipid synthesis, mitochondria proliferation and function, metabolism, and autophagy [6]. There are two mTOR distinct functional complexes: mTORC1 and mTORC2. The mTORC1 involves in controlling the translation initiation step of protein synthesis by directly phosphorylating the translational regulators $\mathrm{S} 6$ kinase (S6K) and eukaryotic translation initiation factor $4 \mathrm{E}$ (eIF4E)-binding protein 1 (4E-BP1) [7, 8]. These regulators, in turn, promote the process of protein synthesis $[7,8]$. It is increasingly apparent that the mTOR signaling pathway impacts most major cellular functions, including cell growth, proliferation, differentiation, development, angiogenesis, and immune response[5].

Understanding the mechanism that involves in regulating the renewal of intestinal epithelial cells is the fundamental of regulating the development and functions of intestinal mucosa and related diseases $[1,9]$. Moreover, the signaling pathways involved in regulating intestinal epithelial cells maturation are also the pathways perturbed during colorectal tumorigenesis, thus understanding the signaling pathways involved in regulating intestinal cell maturation may provide important insights into intestinal tumorigenesis [10]. In the present experiment, we hypothesized that the mTOR signaling pathway may be involved in regulating the renewal of intestinal epithelial cells along CVA. Therefore, the present experiment was conducted to test the correlation between the mTOR signaling pathway and intestinal epithelial cells renewal along CVA.

\section{Materials and Methods}

\section{Materials}

DL- $\beta$-Hydroxybutyrate sodium salt was purchased from J\&K Chemical (Ltd, USA). Trypsin was procured from Promega (Madison, WI, USA). iTRAQ-reagent was purchased from Applied Biosystems (Foster City, CA, USA). Bovine serum alumin (BSA, fraction V), phenylmethylsulfonyl fluoride (PMSF), dithiothreitol (DTT), and other chemical were obtained from Sigma-Aldrich (St. Louis, MO, USA) unless otherwise stated.

Sequential isolation of epithelial cells along CVA

A total of 6 suckling piglets with the age of $21 \mathrm{~d}$ were maintained under general anesthesia and sacrificed by an intravenous (jugular vein) injection of $4 \%$ sodium pentobarbital solution ( $40 \mathrm{mg} / \mathrm{kg}$ born 


\section{Cellular Physiology Cell Physiol Biochem 2016;39:751-759 \begin{tabular}{l|l|l}
\hline DOI: 10.1159/000445665 & $\begin{array}{l}\text { C } 2016 \text { The Author(s). Published by S. Karger AG, Basel } \\
\text { www.karger.com/cpb }\end{array}$
\end{tabular} \\ Yang et al.: mTOR Signaling Pathway Along Crypt-Villus Axis}

weight). Intestinal epithelial cells were isolated using the distended intestinal sac method as previously described with slight modifications [11,12]. The divided mid-jejunum segments were rinsed thoroughly with ice-cold physiological saline solution and incubated at $37^{\circ} \mathrm{C}$ for $30 \mathrm{~min}$ with oxygenated PBS. Then, six "cell fractions" (designated F1 through F6) were collected along CVA using oxygenated isolation buffer (5 mM Na 2 EDTA, $10 \mathrm{mM}$ HEPES pH 7.4, $0.5 \mathrm{mM}$ DTT, 0.25\% BSA, $2.5 \mathrm{mM}$ D-glucose, $2.5 \mathrm{mM}$ L-glutamine, $0.5 \mathrm{mM}$ dl- $\beta$-hydroxybutyrate sodium salt, oxygenated with an $\mathrm{O}_{2} / \mathrm{CO}_{2}$ mixture $\left.(19: 1, \mathrm{v} / \mathrm{v})\right)$. Each of the F1 and F2 fractions were collected after a separate 20 min incubation, F3 and F4 were collected after a separate 25 min incubation, and F5 and F6 were collected after a separate 30 min incubation. Each of the cell fraction was washed twice with oxygenated cell resuspension buffer $\left(10 \mathrm{mM}\right.$ HEPES, $1.5 \mathrm{mM} \mathrm{CaCl} \mathrm{2}_{2}$ $2.0 \mathrm{mM} \mathrm{MgCl}{ }_{2}, \mathrm{pH} 7.4$ ), and centrifuged at $400 \times g$ for $4 \mathrm{~min}$ at $4^{\circ} \mathrm{C}$. The isolated cells were immediately frozen in liquid nitrogen and then stored at $-80^{\circ} \mathrm{C}$ until analysis. The efficiency of fractionation cell was validated by measuring alkaline phosphatase and PCNA as previously described [12]. The activity of alkaline phosphatase was determined using an enzyme assay kit, according to the manufacturer's protocol (Nanjing Jiancheng Bioengineering Institute, Nanjing, China) [13]. The experimental design and procedures used in this study were carried out in accordance with the Chinese Guidelines for Animal Welfare and Experimental Protocols, and approved by the Animal Care and Use Committee of the Institute of Subtropical Agriculture at the Chinese Academy of Sciences.

\section{Western blotting}

The frozen samples were powdered under liquid nitrogen, and lysed in radio immunoprecipitation assay buffer $(150 \mathrm{mM} \mathrm{NaCl}, 1 \%$ Triton X-100, $0.5 \%$ sodium deoxycholate, $0.1 \% \mathrm{SDS}, 50 \mathrm{mMTris}-\mathrm{HCl}$ at pH 7.4, plus a protease inhibitor cocktail (5892791001) purchased from Roche, Shanghai, China). After centrifugation at $10,000 \times \mathrm{g}$ and $4^{\circ} \mathrm{C}$ for $10 \mathrm{~min}$, protein concentration in the supernatant fluid was determined using the Bicinchoninic Acid assay (Beyotime biotechnology, China). All samples were adjusted to an equal protein concentration and then diluted with $2 \times$ loading buffer $[0.63 \mathrm{ml}$ of $0.5 \mathrm{M}$ Tris- $\mathrm{HCl}(\mathrm{pH}$ 6.8), $0.42 \mathrm{ml} 75 \%$ glycerol, 0.125 g sodium dodecyl sulfate (SDS), $0.25 \mathrm{ml} \beta$-mercaptoethanol, $0.2 \mathrm{ml} 0.05 \%$ solution of bromphenol blue, and $1 \mathrm{ml}$ water] to a final volume of $2.5 \mathrm{ml}$ and heated in boiling water for 5 $\mathrm{min}$. After the solution was cooled on ice, it was used for Western blot analysis.

The denatured proteins were separated using SDS-PAGE (10\% gradient gel), transferred to PVDF membranes (Millipore, Billerica, MA) overnight at $12 \mathrm{~V}$ using the Bio-Rad Transblot apparatus (Hercules, CA). The membranes were blocked in 5\% fat-free milk in Tris-Tween buffered saline (TTBS: 20 mMTris/150 $\mathrm{mMNaCl}, \mathrm{pH} 7.5$, and $0.1 \%$ Tween-20) for $3 \mathrm{~h}$ and then incubated with the first antibodies (The antibodies for Akt, p-Akt, mTOR, p-mTOR, S6K, p-S6K, 4E-BP1, p-4E-BP1, and $\beta$-actin were purchased from Cell Signaling Technology, MA, UAS, and the antibodies for eIF4E, Cdk4, Cyclin A, RB3, and $\beta$-tubulin were purchased from Santa Cruz, CA, USA) at $4^{\circ} \mathrm{C}$ overnight with gentle rocking. After washing three times with TTBS, the membranes were incubated at room temperature for $2 \mathrm{~h}$ with horseradish peroxidase-linked secondary antibodies. Finally, the membranes were washed with TTBS, followed by development using Supersignal West Dura Extended Duration Substrate according to the manufacturer's instructions (Pierce, Rockford, IL). The images were detected on chemiluminescence (Applygen Technologies Inc, Beijing, China). For size estimation, a pre-stained protein standard broad range, 10-160 kDa molecular weight (SM0671, Fermentas, Lithuania) were used. Multiple exposures of each Western blot were performed to ensure linearity of chemiluminescence signals. Western blots were quantified by measuring the intensity of correctly sized bands using AlphaImager 2200 (Alpha Innotech Corporation, CA, USA) software [14, 15].

\section{ITRAQ and bioinformatics analysis}

The harvested cells were re-suspended and disrupted in lysis buffer composed of $7 \mathrm{M}$ urea, $2 \mathrm{M}$ thiourea, $4 \%$ w/v CHAPS, 20 mM TBP, 0.2\% Bio-lyte ( $\mathrm{pH} 3-10$ ), and a protease inhibitor cocktail (Roche Diagnostics Ltd, Mannheim, Germany). DNAse I and RNAse A were added to the lysate at final concentrations of $1 \mathrm{mg} / \mathrm{mL}$ and $0.25 \mathrm{mg} / \mathrm{mL}$, respectively. After cell disruption, the protein solution was separated from the cell debris by centrifugation $\left(12,000 \times \mathrm{g}, 5 \mathrm{~min}, 4^{\circ} \mathrm{C}\right)$. The crude protein extracts were further purified using the Ready Prep 2-D Cleanup Kit (Bio-Rad Laboratories, USA) and then subjected to reductive alkylation. The protein concentration was determined using a 2-D Quant Kit (GE Healthcare, USA). Trypsin digestion and iTRAQ labeling were performed according to the manufacturer's protocol (Applied Biosystems, USA). Labeled peptides were fractionated using Ultremex strong cation exchange (SCX) chromatography containing 5 
$\mu \mathrm{m}$ particles (Phenomenex, USA) and then by Strata X C18 chromatography (Phenomenex, USA). A splitless nanoACQuity (Waters, USA) system coupled to Triple TOF was used for analytical separation. Mascot software (version 2.3.02, Matrix Science) was used to simultaneously identify and quantify proteins. Searches were made against the NCBI non-redundant database consisting of mammalian proteins. In order to select differentially expressed proteins, we used the following criteria: 1) the proteins must contain at least two unique high-scoring peptides (peptide confidence $>95 \%$ ) and 2) proteins must have ratios higher than 1.2 or lower than 0.8 , with the relative quantified $p$-values below 0.05 [12]. The WEGO program was used to classify and group the differentially expressed proteins[16]. The proteins related to gene expression were clustered using Cluster 3.0 [17].

\section{Statistical analysis}

All data were subjected to t test using the SAS version 9.2 Program. Data were presented as means \pm SEM, and probability values $<0.05$ were taken to indicate statistical significance.

\section{Results}

Proteins involved in cell cycles decreased and the marker of differentiation increased along CVA

The changes in the expression of proteins related to cell cycle were determined from F1 to F6 in the jejunum of piglets by Western blotting. As shown in Fig. 1A, the amount of $\beta$-tubulin was significantly increased from F1 to F6, reaching a 2.1-fold increase in F6. The amount of Cdk4 and RB3 also increased from F1 to F6, with 2.4-fold and 2.5-fold, respectively. Moreover, the amount of Cyclin A increased 3.1-fold from F1 to F6. The activity of alkaline phosphatase, marker of intestinal enterocytes differentiation, decreased from F1 to F6 with more than about 6.0-fold (Fig. 1A).

Fig. 1. Cell cycle related proteins levels, alkaline phosphatase activity, and Akt phosphorylation (Ser473) and total protein levels along CVA. (A) relative expression of $\beta$-tubulin, Cdk4, Cyclin A, and RB3 and the activity of alkaline phosphatase in each cell fraction were quantified $(\mathrm{n}=6)$. (B) relative phosphorylation (Ser473) and total protein levels of Akt in each cell fraction were quantified $(n=6)$. Significant differences: * quantification of the levels of all the proteins and alkaline phosphatase activity compared to F1, $\mathrm{P}<0.05$. All results are expressed as the mean \pm SEM.

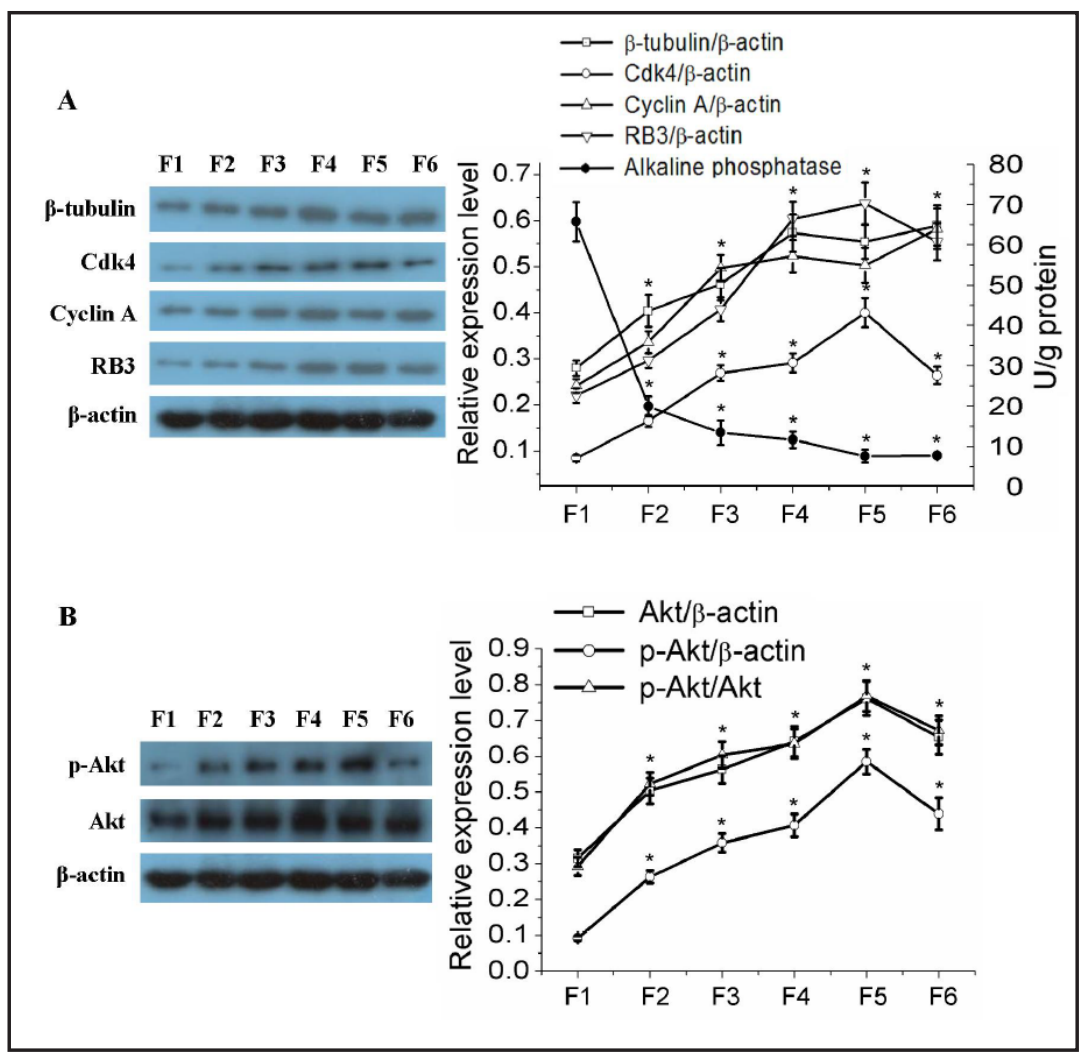




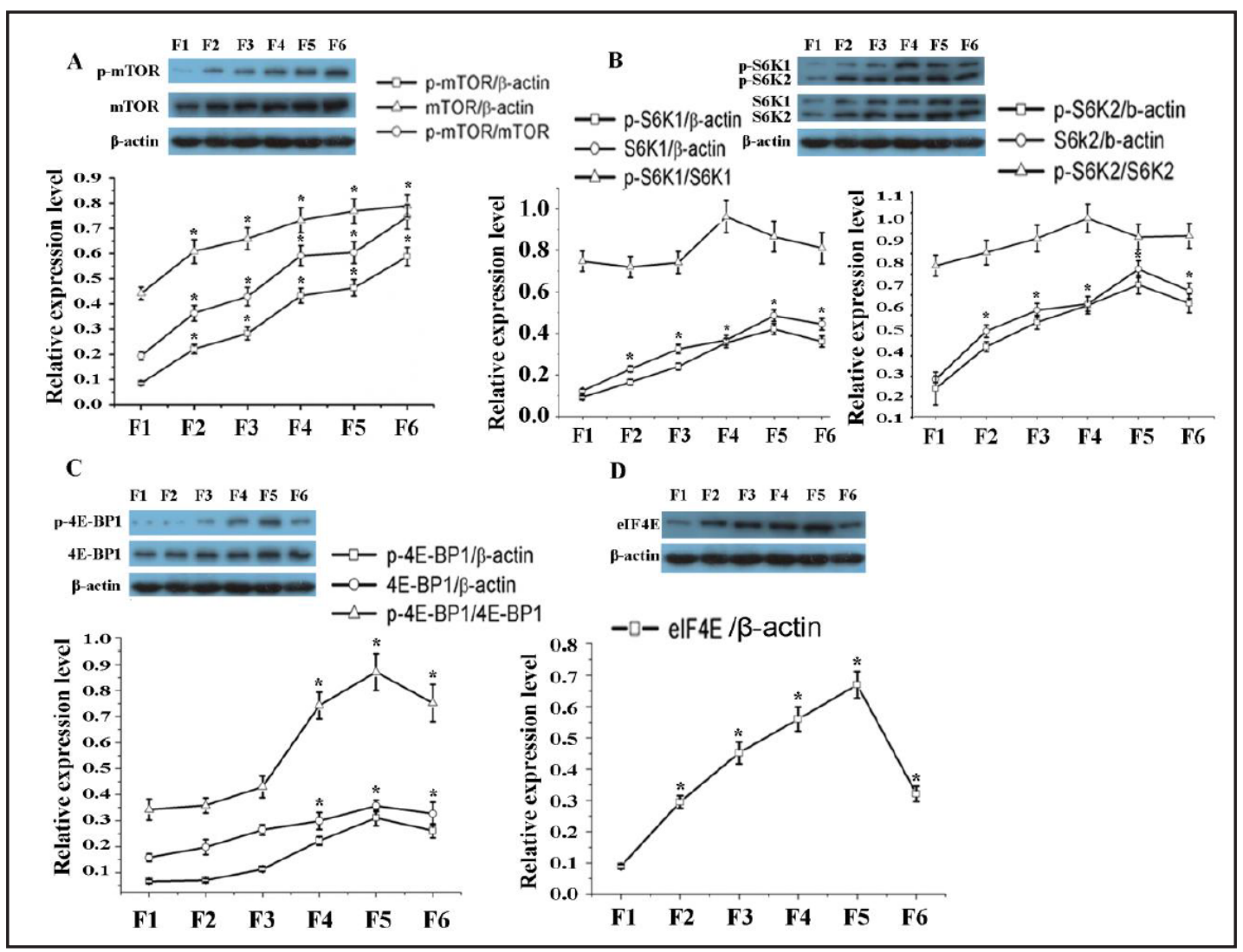

Fig. 2. Relative phosphorylation and total levels of proteins in mTOR signaling pathway along CVA. (A) relative phosphorylation (Ser2448) and total protein levels of mTOR in each cell fraction were quantified (n = 6). (B) relative phosphorylation (Thr389) and total protein levels of S6K1 (85 kDa) and S6K2 (70 kDa) in each cell fraction were quantified $(n=6)$. (C) relative phosphorylation (Thr70) and total protein levels of $4 \mathrm{E}-\mathrm{BP} 1$ in each cell fraction were quantified $(\mathrm{n}=6)$. (D) relative total protein levels of eIF4E in each cell fraction were quantified $(n=6)$. Significant differences: * relative phosphorylation and total levels of proteins in mTOR signaling pathway compared to F1, P $<0.05$. All results are expressed as the mean \pm SEM.

The amount of proteins related to mTOR signaling pathways decreased along CVA

The amount of p-Akt and Akt significantly increased from F1 to F6 with 4.8 and 2.1 fold, respectively (Fig. 1B). The phosphorylation level of Akt (p-Akt/Akt) also increased from F1 to F6 with 2.3-fold (Fig. 1B). The amount of p-mTOR and mTOR, as well as the phosphorylation level of mTOR also increased from F1 to F6 with (Fig. 2A). The amount of p-S6K(1) and S6K(1), as well as p-S6K(2) and S6K(2) increased from F1 to F6, but no significant differences in the phosphorylation levels of S6K(1) and S6K(2) among cell fractions were observed (Fig. 2B). The amount of p-4E-BP1 and 4E-BP1, as well as the phosphorylation level of 4E-BP1 also increased from F1 to F6 with (Fig. 2C). Moreover, the amount of eIF4E also increased from F1 to F6 (Fig. 2D).

The expression of proteins involved in gene expression and antioxidant capacity decreased along CVA

The expression of proteins related to gene expression along CVA was measured using ITRAQ and the results showed that a total of 36 proteins involved in gene expression were differentially expressed along CVA. Among these differentially expressed proteins, the expression of 31 proteins increased from $\mathrm{F} 1$ to $\mathrm{F} 6$ and the expression of 5 proteins decreased from F1 to F6 (Fig. 3). The total antioxidant capacity, as well as the activities of catalase and superoxide dismutase increased from $\mathrm{F} 1$ to $\mathrm{F} 6$, while the contents of malondialdehyde decreased from F1 to F6 (Fig. 4). 
Fig. 3. Relative expression of proteins involved in gene expression along CVA. Relative total protein levels of proteins involved in gene expression were quantified using iTRAQ. The differentially expressed proteins were classified and selected by WEGO program. The proteins involved in gene expression were clustered using Cluster 3.0.
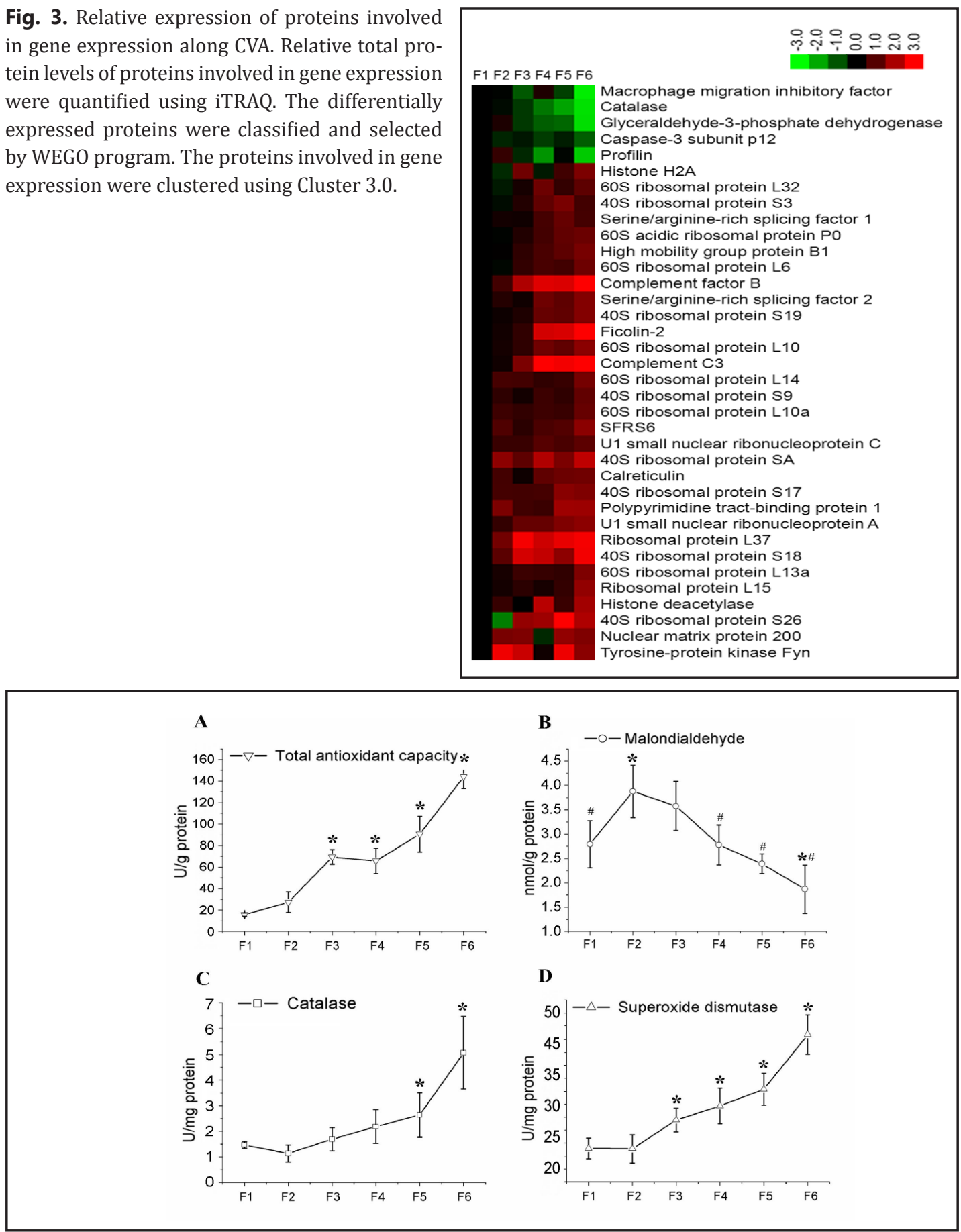

Fig. 4. Antioxidant capacity along CVA. (A) total antioxidant capacity in each cell fraction was quantified ( $\mathrm{n}=$ 6). Significant differences: relative total protein levels of total antioxidant capacity compared to F1, P $<0.05$. All results are expressed as the mean \pm SEM. (B) the contents of malondialdehyde in each cell fraction were quantified $(n=6)$. Significant differences: relative total protein levels of total antioxidant capacity compared to F1, \#relative total protein levels of total antioxidant capacity compared to F2, P $<0.05$. All results are expressed as the mean \pm SEM. (C) the activity of catalase in each cell fraction was quantified $(n=6)$. Significant differences: *relative total protein levels of total antioxidant capacity compared to $F 1, P<0.05$. All results are expressed as the mean \pm SEM. (D) the activity of superoxide dismutase in each cell fraction was quantified $(n=6)$. Significant differences: $*$ relative total protein levels of total antioxidant capacity compared to F1, P < 0.05 . All results are expressed as the mean \pm SEM.

\section{KARGER}




\section{Cellular Physiology Cell Physiol Biochem 2016;39:751-759

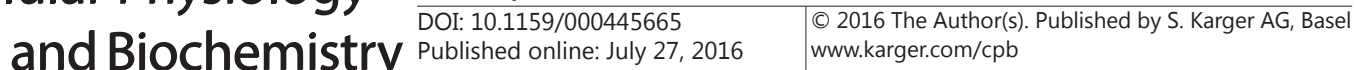 \\ Yang et al.: mTOR Signaling Pathway Along Crypt-Villus Axis}

\section{Discussion}

Organ development requires coordinating multiple cellular processes to yield an organ with proper tissue architecture and size. The mTOR signaling pathway plays a central role in regulating cell growth and proliferation and embryonic development by affecting protein biosynthesis $[18,19]$. However, the rapamycin sensitivity was different between tissues within sensitive speceies [20-22]. Rapamycin treatment inhibited the proliferation of trophoblast more than the inner mass in the E3.5 embryo of mouse [22]. The tissue depended on mTOR signaling for growth may be highly reliant on nutrient sensing for growth control $[19,23]$. Rapamycin treatment inhibited intestinal epithelial growth, morphogenesis and differentiation in zebrafish, which indicated that the development of intestinal epithelium was rapamycin dependent [19]. The results of the present experiment showed that the activity of mTOR signaling pathway in intestinal epithelial cells of piglets was decreased during maturation along CVA as the amount or phosphorylation level of most of the detected proteins involved in mTOR signaling pathway was decreased from crypt to villus tip. The proliferating cells usually have high activity of mTOR signaling pathway because mTOR signaling pathway plays key roles in integrating signals from nutrients and growth factors to regulate cell cycle progression and cell growth coordinately [23].Therefore, the alteration of mTOR signaling pathway along CVA may be resulted from the changes in the maturing state of intestinal epithelial cells. Moreover, the mTOR signaling pathway may play more important roles in regulating the proliferation or early differentiation of intestinal epithelial cells.

In parallel with the reduction in cell proliferation, the expression of genes involved in RNA and protein synthesis was decreased in intestinal epithelia cells during maturation along CVA in mouse, which may be because the proliferation of cells requires a huge number of proteins [9]. In the present experiment, we also showed that the expression of proteins involved in cell cycle and gene expression in intestinal epithelial cells was decreased from crypt to the top of villi in piglets. The mTOR signaling pathway plays key roles in regulating proteins synthesis and its activity decreased from crypt to villus tip [5]. The proliferation and protein synthesis in cultured intestinal cell line (IPEC-1 cells) was also enhanced by L-arginine via activating mTOR signaling pathway [24].Therefore, the mTOR signaling pathway may through affecting protein synthesis to regulate the proliferation of intestinal epithelial cells. Moreover, it was reported that protein synthesis was required for intestinal migration and rapamycin inhibited intestinal cell migration, whileL-arginine activated migration in migrating enterocytes via activating mTOR signaling pathway [25]. Thus, the mTOR signaling pathway was also involved in regulating the migration of intestinal epithelial cells. Activation of mTOR signaling pathway by amino acids protected the intestinal mucosa from fasting-induced atrophy in mice, and the protective effect of amino acids was attenuated by intraperitoneal injection of rapamycin [26]. Overall, the mTOR signaling pathway may be involved in regulating the renewal of intestinal epithelial cells and activation of mTOR signaling pathway is one of the way to treat intestinal mucosal dysfunctions.

Redox mechanisms function in regulating the proliferation of intestinal epithelial cells, and variation in extracellular thiol/disulfide redox state and cellular glutathione/ glutathione disulphide status inhibited the proliferation of CaCo-2 cells [27, 28]. Moreover, dietary supplementation with peroxidized lipids resulted in intestinal redox imbalance and attenuated the proliferation of intestinal epithelial cells [29]. In piglets, dietary sulfur amino acids deficiency also reduced intestinal mucosal antioxidant function and epithelial cells proliferation [30]. The results of the present experiment showed that the antioxidant capacity in intestinal epithelial cells decreased during maturation along CVA, which suggests that the antioxidant status plays important roles in regulating intestinal epithelial cells renewal in piglets as the proliferation of intestinal epithelial cells requires proper redox status [28]. The differentiation and apoptosis of intestinal epithelial cells may also require specific redox status because the proliferating cells are normally associated with a more reduced condition and the cells will undergo growth arrest and apoptosis when the reduced 


\section{Cellular Physiology Cell Physiol Biochem 2016;39:751-759

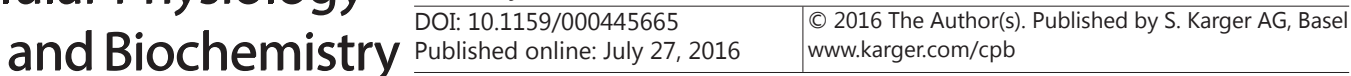 \\ Yang et al.: mTOR Signaling Pathway Along Crypt-Villus Axis}

condition increased [28]. Moreover, cellular antioxidant capacity was interacted with mTOR signaling pathway as mTOR inhibition suppressed antioxidant defense [31, 32]. Therefore, the antioxidant status in intestinal epithelial cells along CVA may also be regulated by mTOR signaling pathway.

In conclusion, the results of the present experiment showed that, in parallel with proteins involved in cell cycle, the amount or phosphorylation level of proteins related to mTOR signaling pathways in intestinal epithelial cells mainly decreased during maturation along CVA. Moreover, the antioxidant capacity and protein synthesis in intestinal epithelial cells also decreased from crypt to villus tip. These results suggest that the mTOR signaling pathway may be involved in regulating the intestinal epithelial cells renewal along cryptvillus axis and it may partly through affecting the antioxidant capacity and protein synthesis of intestinal epithelial cells. Further histological verification is needed to confirm the results of the present experiments.

\section{Abbreviations}

mTOR(mechanistictarget of rapamycin);CVA (crypt-villusaxis); PI3K(phosphoinositide3-kinase); S6K (S6 kinase); eIF4E (eukaryotic translation initiation factor 4E); 4E-BP1 (eIF4Ebinding protein 1); BSA (Bovine serum alumin); PMSF (phenylmethylsulfonyl fluoride); DTT (dithiothreitol); SDS (sodium dodecyl sulfate).

\section{Acknowledgements}

The authors would like to thank Dr. Chengbo Yang for superb technical assistance. The present study was jointly supported by National Natural Science Foundation of China (31330075, 31301988, 31402089, 31272261).

\section{Disclosure Statement}

The authors have declared that no conflict of interest exists.

\section{References}

1 Yang H, Xiong X, Yin Y: Development and renewal of intestinal villi in pigs; in Blachier F, Wu G, Yin Y (eds): Nutritional and Physiological Functions of Amino Acids in Pigs. Springer Vienna, New York, 2013, pp 29-47.

2 Clatworthy JP, Subramanian V: Stem cells and the regulation of proliferation, differentiation and patterning in the intestinal epithelium: Emerging insights from gene expression patterns, transgenic and gene ablation studies. Mech Dev 2001;101:3-9.

3 Fan MZ, Matthews JC, Etienne NM, Stoll B, Lackeyram D, Burrin DG: Expression of apical membrane l-glutamate transporters in neonatal porcine epithelial cells along the small intestinal crypt-villus axis. Am J Physiol Gastrointest Liver Physiol 2004;287:G385-398.

4 Sancho E, Batlle E, Clevers H: Signaling pathways in intestinal development and cancer. Annu Rev Cell Dev Biol 2004;20:695-723.

5 Weichhart T: Mammalian target of rapamycin: A signaling kinase for every aspect of cellular life. Methods Mol Biol 2012;821:1-14.

6 Laplante M, Sabatini DM: mTOR signaling in growth control and disease. Cell 2012;1492:274-293.

7 Mahoney SJ, Dempsey JM, Blenis J: Cell signaling in protein synthesis ribosome biogenesis and translation initiation and elongation. Prog Mol Biol Transl Sci 2009;90:53-107.

8 Fraser CS: The molecular basis of translational control. Prog Mol Biol Transl Sci 2009;90:1-51.

9 Mariadason JM, Nicholas C, L'Italien KE, Zhuang M, Smartt HJ, Heerdt BG, Yang W, Corner GA, Wilson AJ, Klampfer L, Arango D, Augenlicht LH: Gene expression profiling of intestinal epithelial cell maturation along the crypt-villus axis. Gastroenterology 2005;128:1081-1088. 


\section{Cellular Physiology Cell Physiol Biochem 2016;39:751-759 \begin{tabular}{l|l|l} 
DOI: 10.1159/000445665 & $\begin{array}{l}\text { ( ) 2016 The Author(s). Published by S. Karger AG, Basel } \\
\text { www.karger.com/cpb }\end{array}$
\end{tabular}}

Yang et al.: mTOR Signaling Pathway Along Crypt-Villus Axis

10 Kinzler KW, Vogelstein B: Lessons from hereditary colorectal cancer. Cell 1996;87:159-170.

11 Fan MZ, Stoll B, Jiang R, Burrin DG: Enterocyte digestive enzyme activity along the crypt-villus and longitudinal axes in the neonatal pig small intestine. J Anim Sci 2001;79:371-381.

12 Xiong X, Yang H, Tan B, Yang C, Wu M, Liu G, Kim SW, Li T, Li L, Wang J, Wu G, Yin Y: Differential expression of proteins involved in energy production along the crypt-villus axis in early-weaning pig small intestine. Am J Physiol-Gastr L 2015;309:G229-G237.

13 Price DB, Ackland ML, Burks W, Knight MI, Suphioglu C: Peanut allergens alter intestinal barrier permeability and tight junction localisation in caco-2 cell cultures. Cell Physiol Biochem 2014;33:17581777.

14 Yang H, Fu D, Shao H, Kong X, Wang W, Yang X, Nyachoti CM, Yin Y: Impacts of birth weight on plasma, liver and skeletal muscle neutral amino acid profiles and intestinal amino acid transporters in suckling huanjiang mini-piglets. Plos One 2012;7:e50921.

15 Tan JC, Wang Y, Xia Y, Zhang N, Sun XM, Yu T, Lin L: Melatonin protects the esophageal epithelial barrier by suppressing the transcription, expression and activity of myosin light chain kinase through erk1/2 signal transduction. Cell Physiol Biochem 2014;34:2117-2127.

16 Ye J, Fang L, Zheng HK, Zhang Y, Chen J, Zhang ZJ, Wang J, Li ST, Li RQ Bolund L, Wang J: Wego: A web tool for plotting go annotations. Nucleic Acids Res 2006;34:W293-W297.

17 de Hoon MJL, Imoto S, Nolan J, Miyano S: Open source clustering software. Bioinformatics 2004;20:14531454.

18 Wullschleger S, Loewith R, Hall MN: Tor signaling in growth and metabolism. Cell 2006;124:471-484.

19 Makky K, Tekiela J, Mayer AN: Target of rapamycin (tor) signaling controls epithelial morphogenesis in the vertebrate intestine. Dev Biol 2007;303:501-513.

20 Oldham S, Montagne J, Radimerski T, Thomas G, Hafen E: Genetic and biochemical characterization of dtor, the drosophila homolog of the target of rapamycin. Genes Dev 2000;14:2689-2694.

21 Zhang HB, Stallock JP, Ng JC, Reinhard C, Neufeld TP: Regulation of cellular growth by the drosophila target of rapamycin dtor. Genes Dev 2000;14:2712-2724.

22 Murakami M, Ichisaka T, Maeda M, Oshiro N, Hara K, Edenhofer F, Kiyama H, Yonezawa K, Yamanaka S: Mtor is essential for growth and proliferation in early mouse embryos and embryonic stem cells. Mol Cell Biol 2004;24:6710-6718.

23 Fingar DC, Blenis J: Target of rapamycin (tor): An integrator of nutrient and growth factor signals and coordinator of cell growth and cell cycle progression. Oncogene 2004;23:3151-3171.

24 Tan B, Yin YL, Kong XF, Li P, Li XL, Gao HJ, Li XG, Huang RL, Wu GY: L-arginine stimulates proliferation and prevents endotoxin-induced death of intestinal cells. Amino acids 2010;38:1227-1235.

25 Rhoads JM, Niu XM, Odle J, Graves LM: Role of mtor signaling in intestinal cell migration. Am J Physiol-Gastr L 2006;291:G510-G517.

26 Nakamura A, Hara K, Yamamoto K, Yasuda H, Moriyama H, Hirai M, Nagata M, Yokono K: Role of the mtor complex 1 pathway in the in vivo maintenance of the intestinal mucosa by oral intake of amino acids. Geriatr Gerontol Int 2012;12:131-139.

27 Jonas CR, Ziegler TR, Gu LH, Jones DP: Extracellular thiol/disulfide redox state affects proliferation rate in a human colon carcinoma (caco2) cell line. Free Radical Bio Med 2002;33:1499-1506.

28 Aw TY: Cellular redox: A modulator of intestinal epithelial cell proliferation. News Physiol Sci 2003;18:201204.

29 Tsunada S, Iwakiri R, Noda T, Fujimoto K, Fuseler J, Rhoads CA, Aw TY: Chronic exposure to subtoxic levels of peroxidized lipids suppresses mucosal cell turnover in rat small intestine and reversal by glutathione. Digest Dis Sci 2003;48:210-222.

30 Bauchart-Thevret C, Stoll B, Chacko S, Burrin DG: Sulfur amino acid deficiency upregulates intestinal methionine cycle activity and suppresses epithelial growth in neonatal pigs. Am J Physiol-Endoc M 2009;296:E1239-E1250.

31 Bray K, Mathew R, Lau A, Kamphorst JJ, Fan J, Chen J, Chen HY, Ghavami A, Stein M, DiPaola RS, Zhang DN, Rabinowitz JD, White E: Autophagy suppresses rip kinase-dependent necrosis enabling survival to mtor inhibition. Plos One 2012; 7:e41831.

32 Underwood BR, Imarisio S, Fleming A, Rose C, Krishna G, Heard P, Quick M, Korolchuk VI, Renna M, Sarkar S, Garcia-Arencibia M, O'Kane CJ, Murphy MP, Rubinsztein DC: Antioxidants can inhibit basal autophagy and enhance neurodegeneration in models of polyglutamine disease. Hum Mol Genet 2010;19:3413-3429. 